\title{
APRESENTAÇÃO
}

AAUTORA

Maria Aparecida Baccega

Professora Livre-Docente do Departamento de Comunicações e

Artes da ECA-USP. Coordenadora do curso de Pós-Graduação

lato sensu Gestão de Processos Comunicacionais.

\section{MEIOS DE COMUNICAÇÃO NA ESCOLA}

7 rava-se, há algum tempo, uma discussão que apaixona a todos os envolvidos: devem ou não os meios de comunicação, portadores que são dos avanços tecnológicos, estar presentes na Escola? De um lado, os defensores ardorosos dessa presença, alegando que não é possível permitir que a Escola esteja alienada das conquistas tecnológicas que marcam a contemporaneidade. De outro, os que argumentam que a tecnologia é avessa à reflexão e a Escola é o espaço reservado para tal. É evidente que ambos os lados apresentam argumentos sólidos e que se deve buscar o equilíbrio. Mas, será tão simples?

Vivemos num ecossistema comunicativo, que nos impregna a todos e que carregamos conosco em nossas atitudes, em nossos comportamentos, em nossos valores, em nossas decisões. E isso tanto vale para professores quanto para os alunos. Como diz Citelli' ${ }^{1}$, nunca, na história da educação, os dois universos estiveram tão próximos: os mesmos filmes (vistos pela televisão, em geral), os mesmos programas televisivos, os mesmos noticiários, os modismos que assolam toda a sociedade, indistintamente, compõem, hoje, o cenário do processo educacional. $\mathrm{E}$ isso se deve aos meios de comunicação, às tecnologias que vêm permitindo a cada dia avanços até recentemente insuspeitados.

Os conceitos de tempo/espaço já não se marcam como ontem. Um avião que explode as torres do World Trade Center é acompanhado, em tempo real, na sala de casa, por milhões de pessoas em todo o mundo. Basta compararmos com a carta que Caminha escreveu ao rei de Portugal, dando a notícia do descobrimento e o tempo que ela levou para chegar ao destino ou o tempo gasto pelos imigran-

1. CITElli, Adf́lson. Comunicação e educação: os caminhos da linguagem. São Paulo: Senac. 2000. 
tes, no início do século $\mathrm{XX}$, no navio que os transportava da Itália ou outro país para o Brasil: sempre mais de trinta dias.

Os conceitos de perto/longe modificaram-se, portanto, sensivelmente. Os transportes evoluíram, em terra, mar e ar. Logo, os acontecimentos dos mais distantes (geograficamente) pontos da terra influenciam decisivamente nossa cultura, dada a proximidade instaurada.

Fala-se, inclusive, em pensamento único, moldado pelos meios de comunicação que difundem as decisões dos órgãos que controlam o mundo, como o FMI (Fundo Monetário Internacional) e a OMC (Organização Mundial do Comércio). Os habitantes do planeta terão pontos de vista muito assemelhados ou idênticos sobre questões que dizem respeito imediato ao modo de vida de cada país.

Um evento cultural (show de música, por exemplo), que acontece em Londres, estará sendo acompanhado por jovens de todo o planeta. E as bandas de rock, as vestimentas, os gestos serão imitados em todo o mundo.

Está criado, sem dúvida, um novo sensorium, uma nova sensibilidade, uma cultura local definitivamente aberta ao global. E nós, alunos e professores, somos resultado de tudo isso.

Haverá como dizer que a Escola está ou pode ficar fora de tudo isso? Evidentemente que não. Querendo ou não, somos parte dessa cultura, em nossa vida privada e em nossa vida profissional: na família, na escola, no lazer. E assim também nossos alunos. É isso que nos aproxima cada vez mais.

Se nos aproxima, por que está a Escola tão distante da realidade dos alunos? Será que temos receio de nos apresentar como resultado, também, dessa nova cultura? Ou será que consideramos que admitir tal fato implicaria retirar da Escola seu papel de espaço de reflexão e criticidade? Será que consideramos que preservar esse espaço significa fechar os olhos diante da nova (nem tão nova, já) realidade?

E assim vamos perdendo a autoridade que a sociedade sempre nos delegou para que formássemos cidadãos.

\section{CULTURAS E TECNOLOGIAS}

É preciso, porém, que tornemos mais abrangente a discussão. Já não se trata exatamente de utilizar-se ou não dos meios de comunicação na Escola, uma vez que eles compõem o fazer e o pensar de alunos e professores. Logo, eles lá estão. Trata-se, isso sim, de nos perguntarmos de que modo a Escola pode cumprir seu objetivo maior - formar cidadãos críticos - a partir dessa nova realidade. A utilização, e em que medida, das novas tecnologias deve estar subordinada a esse objetivo. Que fazer para que a Escola retire suas máscaras conservadoras e se encontre com a sociedade do presente, ajudando a construir um futuro em que as pessoas sejam mais iguais e tenham seus direitos respeitados? 
$\mathrm{O}$ mero uso das tecnologias não responde ao desafio. O que pode acontecer é, com tal uso, exacerbar-se o caráter conservador e distante da contemporaneidade que ainda caracteriza, no geral, a Escola.

A Escola não é mais, hoje, o único lugar onde se adquire o saber. O saber está presente em todos os interstícios da sociedade, carregado pelos meios de comunicação. Em geral o saber difundido na sociedade não é o mesmo pelo qual a Escola ainda briga. E o modo como se difunde na sociedade esse saber é, em geral, muito mais agradável que o modo de agir da Escola: o saber descentrado vem manifestado em várias linguagens; o saber da Escola, em geral, apenas na linguagem verbal.

A questão, portanto, não se centra no uso ou não das tecnologias (elas devem ser usadas de acordo com o planejamento da Escola); a questão está centrada em um choque de culturas que é preciso harmonizar: a cultura da sociedade como um todo, a cultura que os alunos trazem versus a cultura que predomina na Escola de que os professores são porta-vozes.

Para Martín-Barbero, "só quando assumir a tecnicidade mediática como dimensão estratégica da cultura é que a Escola poderá inserir-se nos processos de mudança que nossa sociedade atravessa. Para isso, a Escola deve interagir com os campos de experiência em que hoje se processam as mudanças: desterritorialização/ relocalização das identidades, hibridação da ciência e da arte, das literaturas escritas e audiovisuais, organização dos saberes a partir dos fluxos e redes através dos quais hoje se mobiliza não só a informação como também o trabalho e a criatividade, o intercâmbio e a publicização de projetos, de pesquisas, de experimentações estéticas" ${ }^{2}$.

O problema fundamental é como inserir a Escola nessa nova realidade de conhecimentos descentrados, de culturas diferentes, de sensibilidades outras. Não será, evidentemente, considerando o uso de tecnologias como fator de modernização da Escola que tal objetivo será atingido. É preciso incluir no planejamento as diferentes linguagens da cultura, dar espaço à oralidade, às narrativas pessoais e audiovisuais (por que não discutir a novela das 8 que tanto alunos quanto professores acompanham, diariamente ou não), às diferenças no lugar do igual, ao movimento no lugar do estático (e a disciplina autoritária perde lugar) e o professor passa a ser o coordenador das atividades, sujeito pleno de interrogações, cujas respostas se constituem em processos a serem trilhados juntamente com seus alunos.

Assim, poderemos formar cidadãos livres e "gente livre significa gente capaz de saber ler a publicidade e entender para que serve, e não gente que deixa

2. MARTÍN-BARBERO, Jesus. Comunicación-educación: una relación estratégica. Nómadas, Santa Fé de Bogotá: Fundación Universidad Central, n. 5, set. de 1996. p. 19. 
massagear o próprio cérebro; gente que seja capaz de distanciar-se da arte que está na moda, dos livros que estão na moda, gente que pense com a sua cabeça e não com as idéias que circulam ao seu redor"3.

\section{ESCOLA COMO MEDIAÇÃO}

Um dos caminhos para a consecução desse objetivo é a desmistificação do que está por trás da telinha da televisão, sobretudo. Também o modo que são feitos os programas de rádio, os jornais e as revistas.

Como já dizíamos no número 1 da revista Comunicação \& Educação ${ }^{4}$, consideramos fundamental a consciência de que vivemos num mundo editado, em que a parte apresentada, a qual já passou por numerosos filtros, atendendo a variados interesses, nos é apresentada como o todo, num processo metonímico perverso.

"Editar é construir uma realidade outra, a partir de supressões ou acréscimos em um acontecimento. Ou, muitas vezes, apenas pelo destaque de uma parte em detrimento de outra. Editar é, portanto, reconfigurar alguma coisa, dando-lhe novo significado, atendendo a determinado interesse, buscando um determinado objetivo, fazendo valer um determinado ponto de vista"s. É o resultado dessa edição que constrói nossa visão de mundo, que preenche nosso imaginário sobre outras realidades, outras pessoas, outros valores. É ela que alicerça a cultura na qual vivemos. É essa edição que está presente nas novas sensibilidades que permeiam essa cultura.

Compete à Escola e também à educação não formal tornar claro que é esse modo como são construídos os programas dos meios de comunicação. Além disso, também os aspectos técnicos têm que ser do conhecimento dos alunos: aspectos lingüísticos, gramática das imagens, planos, o processo de ocultamento/demonstração etc.

Como lembra Orozco, "parto do reconhecimento de que não se nasce telespectador, mas sim que o telespectador e a teleaudiência, enquanto ente coletivo, vão se conformando a partir das suas experiências concretas de interação com a TV e de outras instituições socializadoras, as quais intervêm nessas experiências" 6 . A Escola, portanto, não tem, sozinha, a atribuição de formar leitores críticos dos meios de comunicação, base da formação do cidadão crítico que saberá ler o mundo editado para, a partir dele, construir novas variáveis históricas.

3. MARTÍN-BARBERO, Jesus. Desafios culturais da comunicação à educação. Comunicação \& Educação. n. 18. São Paulo: CCA-ECA-USP/ Segmento, maio/ago, de 2000, p. 60.

4. BACCEGA, Maria Aparecida. Do mundo editado à construção do mundo. Comunicação \& Educação. São Paulo: CCA-ECA-USP/ Moderna, n. 1, set./dez. de 1994. p. 7-14.

5. BACCEGA, Maria Aparecida. Do mundo editado... op. cit. p. 8.

6. OROZCO GOMEZ, Guillermo. Teleaudiência: premissas para uma pedagogia. Comunicação \& Educação.

São Paulo: CCA-ECA-USP/ Segmento, n. 18, maio/ago. de 2000. p. 63. 
Mas não se pode negar que a Escola tem um enorme poder de mediação na construção de significados. E não pode alienar-se dessa tarefa.

"Considerar as práticas Escolares tendo em vista os veículos de comunicação e as novas tecnologias passa por pelo menos três direções fundamentais: o diálogo crítico com os meios; o reconhecimento das possibilidades operacionais, isto é, os alunos devem aprender um pouco como se produzem as linguagens da mídia; a melhoria na infra-estrutura tecnológica da própria Escola. Problema cuja solução depende, basicamente, das políticas oficiais." "

As tecnologias, como dissemos, estão presentes na Escola pelo simples fato de na Escola estarem pessoas, sujeitos culturais que as carregam em seus fazeres e seus pensares. Mediar a construção de significados dessas tecnologias e colocálas a serviço dos objetivos educacionais é o que se pretende. ${ }^{8}$

\section{ARTIGOS NACIONAIS}

Qual o lugar das tecnologias na educação dos portadores de deficiências? É o que discute o artigo Informática na educação especial, de Amélia Leite de Almeida. Partindo da premissa de que "não basta ter a informação diante de si para que ela se transforme em conhecimento", a autora lembra que é preciso, para tal, trabalhar "com e em ambientes interativos nos quais a tecnologia atue como estímulo à cognição social".

Focaliza "o potencial das novas tecnologias em romper o isolamento daqueles alunos que, por barreiras arquitetônicas e sociais, têm impedido seu acesso à informação de forma interativa", sem perder-se de vista que, por maior que seja o grau de desenvolvimento tecnológico, "ainda é o ser humano quem melhor desempenha o papel de mediador".

Telenovela e vida cotidiana, de Roberta Manuela Barros de Andrade, traz uma contribuição para se pensar a telenovela na sua relação com o cotidiano vivido e o cotidiano ficcional, o que muito colabora para que se discuta esse gênero em sala de aula. Segundo a autora, uma das marcas da telenovela é a redundância, a qual, "longe de ser um elemento que poderia caracterizá-la como uma narrativa menor é, de fato, um dos componentes mais importantes da fidelidade ao gênero".

7. CITElli, Adílson. Meios de comunicação e práticas escolares. Comunicação \& Educação. São Paulo: CCA-ECA-USP/ Segmento, n. 17, jan./abr. de 2000. p. 34.

8. Ver também MORAIS, Gelcivânia Mota Silva. Novas tecnologias no contexto Escolar. Comunicação \& Educação. São Paulo: CCA-ECA-USP/ Segmento, n. 18, maio/ago. de 2000. p. 15-21. SOARES, Ismar de Oliveira. Educomunicação: um campo de mediações. Comunicação \& Educação. São Paulo: CCA-ECAUSP/Segmento, n. 19, set./dez. de 2000. p. 12-24. 
Mostrando os diferentes regimes de assistência, modos que a telenovela é acompanhada pelos telespectadores, Roberta discute como os significados se constroem de maneiras diferentes num ou noutro ambiente.

Outro ponto importante abordado nesse artigo é o papel dos chamados textos secundários - aqueles que circulam nas revistas ditas especializadas, nos suplementos de jornais etc. - formando a intertextualidade que se destaca na construção dos significados da telenovela. Narrativa que permeia a cultura brasileira, a telenovela pode estar presente nas Escolas, onde a discussão de suas temáticas poderá mostrar-se excelente instrumental educativo.

"Ensinar arte como expressão de sentimentos e emoções é um estereótipo que acompanha a profissão, mas ao mesmo tempo é uma idéia abrangente, rica e polêmica. Uma primeira evidência de sua abrangência é a discussão em torno do próprio conceito de arte." Assim Irene Tourinho começa seu artigo Emoções e sentimentos: polêmicas sobre o ensino de arte, que publicamos neste número.

Passando pela discussão da aura, das relações entre Filosofia e Estética, da arte como expressão, a autora vai mostrando como "não apenas as circunstâncias materiais, mas também as sociais, culturais e históricas devem ser consideradas. Pensar a arte unicamente como expressão de sentimentos e emoções resulta ou na supervalorização do artista ou do objeto". O ensino da arte na contemporaneidade exige requisitos, alguns dos quais estão discutidos no artigo.

\section{ARTIGO INTERNACIONAL}

Sistemas educativos entre máquinas e redes é o artigo de Bruno Olivier que traduzimos para a seção internacional. Trata-se de um alerta sobre o papel das tecnologias da informação e da comunicação na sociedade. O autor nos mostra os perigos desse novo "deus" em todos os segmentos da sociedade e, sobretudo, no campo da educação. A informática, por exemplo: para que serve? Como deve organizar-se sua distribuição na Escola? E o ensino a distância? Como ele conseguirá cumprir o objetivo básico da educação que é o de socializar?

O uso das tecnologias, até agora, tem-se mostrado mais um fator de discriminação. "No plano internacional, a desigualdade tecnológica aumenta cada vez mais. Devemos lembrar que, enquanto a Califórina, nos EUA, gasta $400 \mathrm{mi}$ lhões de dólares substituindo os computadores de seu sistema escolar, em todo o Chade só existem nove velhos PCs (....) Assim constrói-se um mundo no qual as brechas entre os inforicos e os infopobres se acrescenta a cada dia, tanto entre os países do Norte quanto os do Sul, como também dentro de cada país." Qual o papel da comunicação/educação nessa nova realidade? É o que o artigo procura responder. 


\section{ENTREVISTA}

Arte de uma pérola negra, título da entrevista que Ruth de Souza concede a Comunicação \& Educação, é a medida certa das palavras que revelam a trajetória de uma mulher negra que nunca vacilou em defender seu trabalho, seus pontos de vista, fazendo da arte de interpretar seu modo de vida. Ela fala das dificuldades de espaço de trabalho para o ator negro. Mas afirma que já melhorou muito, destacando seu último papel como dona Mocinha, na novela $O$ clone: "O público aceitou perfeitamente aquela mãe negra e aquela avó negra para aquele menino que era a estrela da história (...) toda a criançada hoje, que gosta da dona Mocinha, não reparou que a dona Mocinha é negra e isso é muito bom para fazer essa unidade racial no Brasil".

\section{CRÍTICA}

A questão étnica permeia a discussão que nos traz o professor Arthur Versiani Machado, com sua crítica ao filme Exodus, no artigo: Exodus: uma introdução à questão judaico-palestina. O filme de 1960, que ganhou recentemente nova edição em vídeo, é a oportunidade para se levar à sala de aula a discussão sobre temática tão atual. Os dados históricos e a interpretação do filme possibilitam um instrumental fantástico para o educador que tem como objetivo fazer com que os alunos compreendam o problema sem preconceitos. $\mathrm{O}$ autor destaca como o mais grave malefício dos meios de comunicação de massa, e portanto também do cinema, o de criar consensos em torno das questões mais variadas e diversas da vida humana, levando certamente à reafirmação de estereótipos: "a modernidade fabrica e difunde seus mitos através da indústria cultural. $\mathrm{O}$ estereótipo do árabe fanático e sanguinário e, por oposição a imagem do judeu como vítima indefesa são exemplos desta padronização das representações mentais".

\section{DEPOIMENTO}

Por detrás da notícia é o artigo da especialista em gestão de processos comunicacionais Rita Amorim, assessora de imprensa do Hospital do Coração do Hospital das Clínicas, Incor. A autora destaca o período em que o governador Mário Covas esteve internado no Hospital, onde veio a falecer. Ela fala sobre a importância da atuação da assessoria de imprensa para garantir ao público informações confiáveis, de fonte segura, sem ferir a ética médica e jornalística, além do direito do paciente à privacidade. Para a autora: "Não está longe da verdade definir o papel do assessor de imprensa como um gestor da comunicação, que deve estar apto a identificar as necessidades e interesses de comunicação/informação dos diferentes agentes envolvidos na divulgação da notícia, desde a origem desta, passando pela sua produção, até seu consumidor final, o público." 


\section{EXPERIÊNCIA}

Educação para os meios: um projeto com vídeo é o artigo do professor Mar$\cos$ Aurélio Pereira, que trata de sua experiência com o vídeo em sala de aula. Ele reflete sobre as dificuldades e os problemas do trabalho pedagógico com os meios de comunicação e afirma: "a escola passou do livro didático para os jornais, destes para a televisão, depois para o vídeo e, mais recentemente, para a Internet, sem mensurar as implicações na sua manipulação". Ou seja, o professor Marcos Aurélio está preocupado com a especificidade de cada uma das linguagens e como, muitas vezes, se trabalham com elas sem se levar esse importante detalhe em conta.

\section{POESIA}

O poeta deste número é Vinicius de Moraes, o poeta das musas e do amor, da alegria e da saudade, de Rosa de Hiroshima. Da diplomacia Vinicius de Moraes veio nos brindar com seus poemas, peças de teatro e letras de inesquecíveis canções. Sua Mensagem à poesia é um canto à solidariedade e à vida.

\section{SERVIÇOS}

Memorial do Imigrante - um museu em movimento, de Marco Antônio Xavier, é uma reflexão sobre a finalidade dos museus, uma contribuição para que se pense sobre a importância destas instituições não apenas como acervo da memória, mas como parâmetro do que se seleciona da realidade para permanecer como memória. Ou seja, peça de museu permanece porque tem relação com o hoje. Diz o autor: "Um museu é um lugar de preservação que tem alguma relação com o ser humano, seus atos, vontades e como ele encara a natureza". Por isso a importância do Memorial do Imigrante que, segundo o autor, "não é somente um museu, mas um complexo de serviços culturais com base no seu acervo, basicamente composto por objetos de uso cotidiano, de imigrantes e seus descendentes (...)".

\section{VIDEOGRAFIA}

Maria Ignês Carlos Magno nos propõe um exercício sobre a Arte do cinema. A autora selecionou para este número os filmes: Corrida de automóveis para meninos e Carlitos no estúdio, ambos de Charles Chaplin; $O$ último magnata, de Elia Kazan; $A$ noite americana, de François Truffaut; Idade do ouro, de Luis Buñuel, $O$ gabinete do dr. Caligari, de Robert Wiene; e M, o vampiro de Düsseldorf, de Fritz Lang. Vale a pena conferir.

\section{BOLETIM BIBLIOGRÁFICO}

Bibliografia sobre telenovela brasileira, assinado por Anamaria Fadul, rese- 
nha as últimas contribuições de estudiosos sobre esta temática. Bibliografia sobre comunicação e educação, assinado por Ismar de Oliviera Soares, destaca importantes contribuições dadas a esse campo por publicações oficiais, dissertações acadêmicas e, inclusive, livros de charges.

Endereços úteis na Internet é uma contribuição para os internautas que não gostam de perder tempo e preferem utilizar a rede mundial de computadores para pesquisas proveitosas.

\section{ATIVIDADES EM SALA DE AULA}

Ruth Ribas Itacarambi propõe para os professores duas atividades pedagógicas com Comunicação \& Educação n. 25. Preocupada com o papel que a escola desempenha na atualidade, a autora reflete sobre o que significa ensinar e qual a finalidade da escola. Ela responde com a afirmação de que é preciso que os conteúdos possibilitem o desenvolvimento do jovem para o século XXI. Neste sentido, propõe uma atividade que discute a estrutura seriada da telenovela e os diferentes modos de assistir e, uma outra, que destaca o objetivo de se discutir a sociedade da informação.

Resumo: $\mathrm{O}$ artigo discute a presença dos meios de comunicação e das novas tecnologias na escola. Parte da polêmica entre aqueles que se posicionam favoravelmente e aqueles que são contrários para reafirmar que esta não é uma questão de vontade, mas de reconhecer que, queiramos ou não, eles já estão presentes na escola, pois fazem parte do cotidiano e da cultura de alunos e professores. O problema mais importante a resolver é saber como utilizá-los para possibilitar uma educação adequada à realidade da cultura midiática, tendo a Escola o papel de mediação, capacitando os alunos para serem cidadãos críticos, livres e que saibam pensar e escolher por si próprios.

Palavras-chave: meios de comunicação, Escola, cultura, novas tecnologias

\section{(The media in the school)}

Abstract: The article discusses the presence of the media and of new technologies in the school. It begins by discussing the controversy there is among those who favor and those who are against such a presence in order to emphasize this is not a matter of will, rather, that we have to acknowledge that whether we like it or not, the media is already present in the school since they are a part of the daily life and of the culture of both students and teachers. The most important problem to solve is to know how to use them in order to allow for an education that is adequate for the reality of the mediatic culture, with the school having a mediation role, qualifying the students to be free, critical citizens who can think and make decisions on their own.

Key words: media, school, culture, new technologies 